\title{
PERANCANGAN SISTEM INFORMASI PENYEWAAN PAKET PERNIKAHAN DAN RESEPSI DI YULIZAL WEDDING BERBASIS JAVA NETBEANS
}

\author{
Putri Nurjannah Marasabessy ${ }^{1}$, Kursehi Falgenti ${ }^{2}$, dan Alhidayatuddiniyah T.W ${ }^{3}$ \\ ${ }^{1,2,3}$ Fakultas Teknik dan Ilmu Komputer, Universitas Indraprasta PGRI \\ putri.marsy98@gmail.com ${ }^{1}$
}

\begin{abstract}
Abstrak
Tujuan Penelitian adalah dapat mengoptimalkan proses penyewaan paket pernikahan dan resepsi. Metode penulisan yang digunakan adalah metode grounded research yaitu suatu metode penelitian berdasarkan pada fakta dan menggunakan analisis perbandingan dengan tujuan mengadakan generalisasi empiris menetapkan konsep, membuktikan teori, mengembangkan teori, pengumpulan dan analisis data dalam waktu yang bersamaan. Penulis menarik kesimpulan bahwa sistem informasi yang dibangun dapat mengoptimalkan proses penyewaan paket pernikahan dan resepsi di yulizal wedding dan mempermudah pembuatan laporan data penyewaan paket pernikahan dan resepsi agar lebih akurat dan efisien.
\end{abstract}

Kata kunci: : Penyewaan, Wedding Organizer, Java, MySQL.

\begin{abstract}
The research objective is to optimize the process of renting wedding packages and receptions. The writing method used is a grounded research method which is a research method based on facts and uses comparative analysis with the aim of carrying out empirical generalizations to set concepts, prove theories, develop theories, collect and analyze data at the same time. The author draws the conclusion that the information system that was built can optimize the process of renting wedding packages and receptions at Yulizal Wedding and simplifies the making of wedding package data and reception reports to be more accurate and efficient.
\end{abstract}

Keywords: Rental, Wedding Organizer, Java, MySQL

\section{Pendahuluan}

Perkembangan teknologi saat ini semakin berkembang pesat, pemenuhan kebutuhan terhadap suatu informasi saat ini tidak lepas dari pemakaian dan pemanfaatan komputer, dibandingkan dengan proses sebelumnya, dengan adanya sistem informasi yang terkomputerisasi, maka pekerjaan yang dilakukan akan menjadi lebih cepat, tepat dan akurat. Selain itu, perkembangan teknologi informasi dan komunikasi mendorong lahirnya pelayanan-pelayanan atau berbagai jenis kegiatan yang berbasis internet dan elektronik.

Yulizal wedding merupakan salah satu dari beberapa wedding organizer yang berlokasi di Depok. Transaksi penyewaan paket pernikahan dan resepsi di Yulizal Wedding sampai saat ini masih menggunakan metode manual, dimana kegiatan seperti ini dirasakan sangat tidak efisien. Perancangan sistem informasi dapat membantu dalam mengatasi masalah yang dihadapi oleh Yulizal Wedding. Metode perancangan sistem informasi untuk transaksi penyewaan paket 
pernikahan dan resepsi di Yulizal Wedding berfungsi untuk menghasilkan rancangan sistem informasi yang efisien yang dapat menambah nilai bisnis dari organisasi tersebut.

Dari uraian pada tujuan penelitian, maka peneliti memberi sejumlah tujuan penelitian sebagai berikut:

1. Mengoptimalkan proses penyewaan paket pernikahan dan resepsi di yulizal wedding

2. Mempermudah pembuatan laporan data penyewaan paket pernikahan dan respsi agar lebih akurat dan efesien.

Manfaat penelitian dalam penelitian ini adalah sebagai berikut :

1. Dapat berguna dalam menambah wawasan dan pengetahuan dibidang Penyewaan, khususnya Wedding Organizer dan menambah penerapan teori pada kuliah yang sedang dijalani.

2. Penelitian ini untuk membantu dan mempermudah dalam pelayanan penyewaan, data penyewa dan pembuatan laporan.

3. Hasil ini dapat memberikan tambahan pengetahuan dan dapat menjadi bahan referensi, bagi pihak-pihak yang akan mengkaji informasi dan melakukan penelitian yang sama.

\section{Metode Penelitian}

Menurut (Marzuki, 2013) "Metode penelitian merupakan suatu proses yang bertujuan untuk menemukan, mengembangkan, dan menguji suatu pengetahuan dengan cara mengumpulkan, mencatat, dan menganalisis informasi data yang dilakukan dengan sabar, hati-hati, terencana dan sistematis serta berdasarkan ilmu pengetahuan".

$$
\text { Pada penelitian ini, penulis }
$$
menggunakan metode penelitian Grounded research. Grounded research adalah suatu metode penelitian yang mendasarkan diri kepada fakta yang menggunakan analisis perbandingan untuk mengandakan generalisasi teori, dan mengembangkan teori dimana pengumpulan data dan analisis data berjalan pada waktu yang bersamaan. Dari definisi diatas, maka terlihat bahwa metode yang digunakan dalam Grounded research adalah reaksi terhadap metode penelitian yang asasnya verifikasi teori. Dalam Grounded Research data merupakan sumber teori,dan teori disebut Grounded Research Karena teori tersebut berdasarkan fakta.

Tujuan Grounded Research adalah untuk melakukan generalisasi empiris, menetapkan konsep-konsep, membuktikan teori dan mengembangkan teori. Metode yang digunakan dalam Grounded Research adalah studi-studi perbandingan berjutuan untuk menentukan seberapa jauh suatu gejala berlaku umum. Penelitian juga bertujuan untuk mempelajari suatu kasus atau gejala dengan membandingkan gejala atau kasus tersebut dengan kasus gejala serupa. Perbandingan demikian akan menjelaskan unsure-unsur baru khas dari kasus yang sedang dipelajari.

\section{Metode Pengumpulan Data}

Metode yang digunakan untuk pengumpulan data secara pengambilan keterangan yang dibutuhkan untuk merancang program dalam penelitian ini dilakukan dengan cara :

\section{Metode Lapangan}

Dilakukan peneliti secara langsung untuk mengumpulkan data-data yang berhubungan dengan perancangan aplikasi penyewaan wedding organizer dengan melakukan observasi yang mempelajari dan mengamati dan mempelajari sistem yang berjalan di Yulizal Wedding serta dilengkapi dengan wawancara dengan pemilik tempat penyewaan wedding organizer untuk mendapatkan data yang tidak dapat diraih dengan observasi dan untuk melengkapi data yang didapatkan dari observasi.

\section{Studi Pustaka}

Yaitu metode pengumpulan data dengan cara mengumpulkan data dan informasi dari kutipan-kutipan, buku-buku, serta hasil laporan lainnya yang berkaitan dengan penelitian ini. Peneliti juga mendatangi perpustakaan Universitas Indraprasta untuk melihat dan membaca skripsi yang terkait dengan sistem penyewaan gedung serbaguna dan wedding organizer.

\section{Hasil dan Pembahasan}

Menurut (Sutabri, 2012) Rancangan Data 
Flow Diagram (DFD) pendekatan analisis terstruktur diperkenalkan oleh DeMarco (1978) dan Gane Sarson (1979) melalui buku metedologi struktur analisis dan desain sistem informasi.

\section{Diagram Konteks}

Diagram konteks adalah sebuah diagram sederhana yang menggambarkan hubungan antara entity luar, masukkan dan keluaran dari sistem (Kristanto, 2011) Diagram ini dibuat untuk menggambarkan sistem secara umum dari keseluruhan sistem yang ada. Diagram Konteks yang diusulkan pada Penyewaan Paket Pernikahan dan Resepsi di Yulizal Wedding, yatitu:

1) Pemilik Yulizal Wedding

2) Pelanggan

3) Admin

Dibawah ini adalah gambar Diagram Konteks yang diusulkan sebagai berikut:
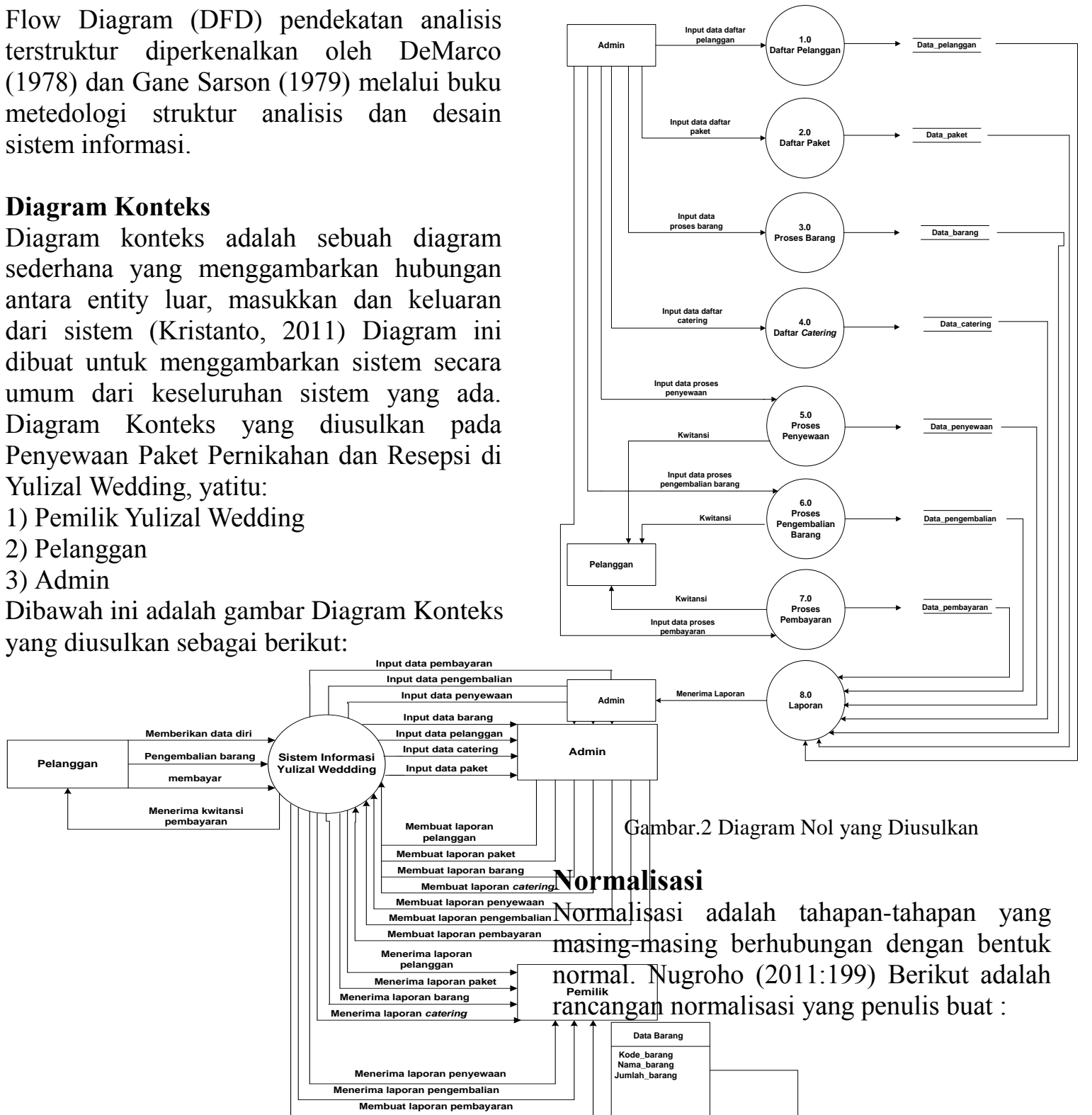

Gambar.2 Diagram Nol yang Diusulkan

Gambar.1 Diagram Konteks yang Diusulkan

\section{Diagram Nol}

Diagram ini dibuat untuk menggambarkan tahapan proses yang ada di dalam Diagram Konteks, yang penyebarannya lebih terperinci. Tahapan proses tersebut diantranya adalah:
1) User
2) Pendataan
3) Cek Paket
4) Penyewaan
5) Laporan

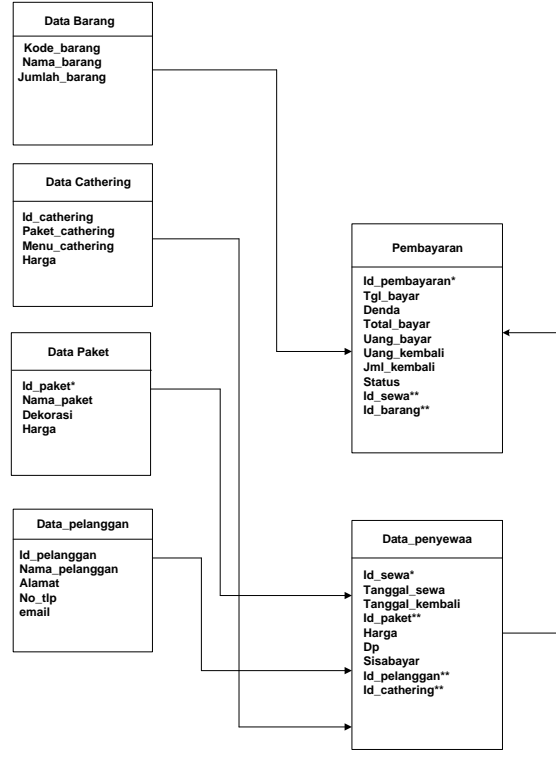

Gambar.3 Normalisasi 2NF 


\section{Entity Relationship Diagram (ERD)}

Entity Relationship Diagram (ERD) adalah suatu model data yang dikembangkan berdasarkan objek. Sutanta (2011:91). Adapun ERD yang penulis usulkan dapat digambarkan sebagai berikut:

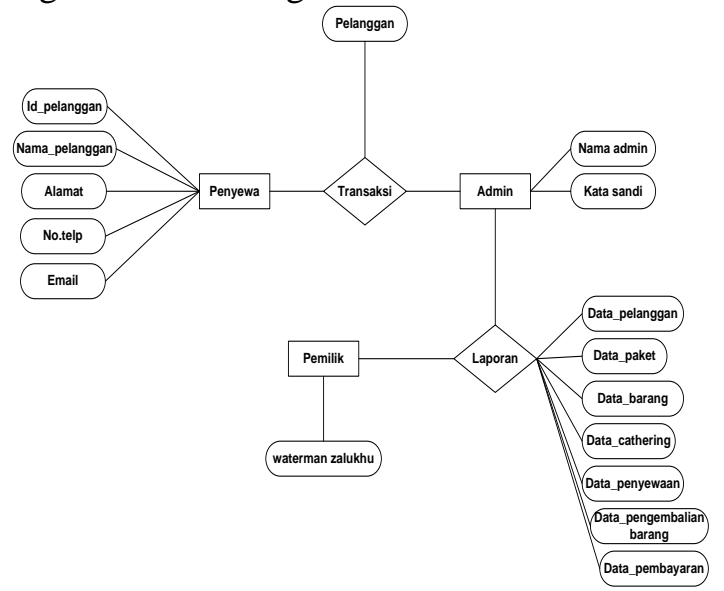

Gambar.4 ERD yang diusulkan

Selanjutnya penulis membuat aplikasi menggunakan java dan database mysql. Berikut ini adalah tampilan dari Perancangan Sistem Informasi Penyewaan Paket Pernikahan dan Resepsi di Yulizal Wedding Berbasis Java Netbeans :

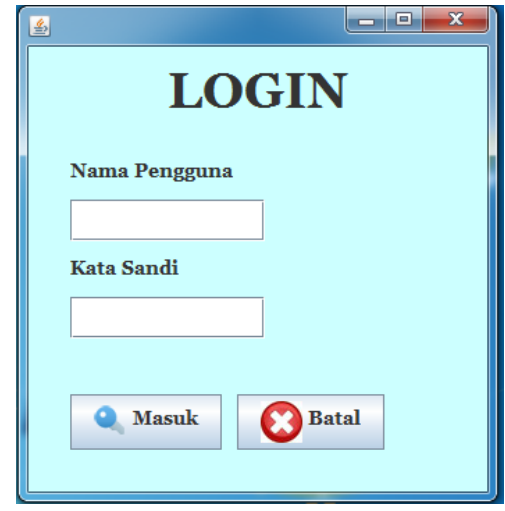

Gambar 5. Login

Tampilan menu login ini muncul di awal saat pengoperasian program aplikasi sistem informasi penyewaan paket pernikahan di Yulizal Wedding untuk diisi oleh admin. Masukkan nama pengguna dan kata sandi sesuai dengan hak akses supaya bisa mengoperasikan sistem. Jika nama pengguna dan kata sandi sesuai, lalu klik tombol masuk, maka akan masuk ke tampilam menu utama.

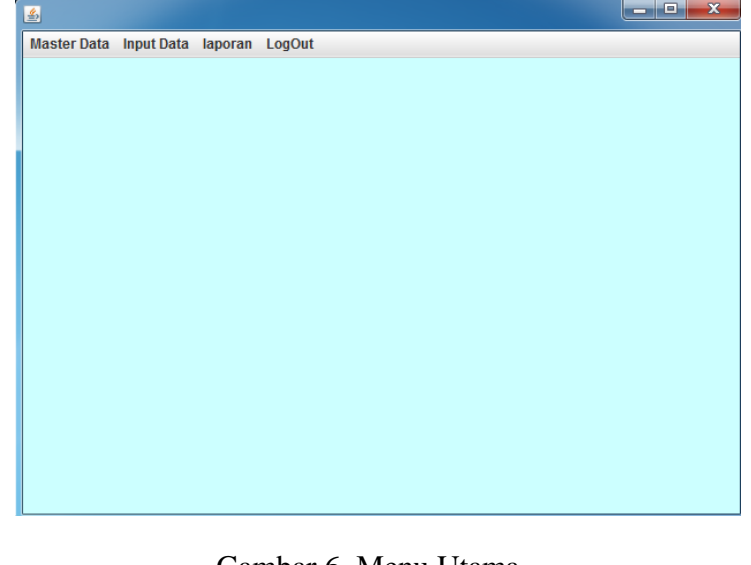

Gambar 6. Menu Utama

Pada tampilan menu utama tersedia beberapa mеnu bar untuk memudahkan pengguna mengakses beberapa form inputan seperti form data pelanggan. Form data paket, form data penyewaan, form data catering, dan form laporan transaksi yang terlampir di dalam menu bar.

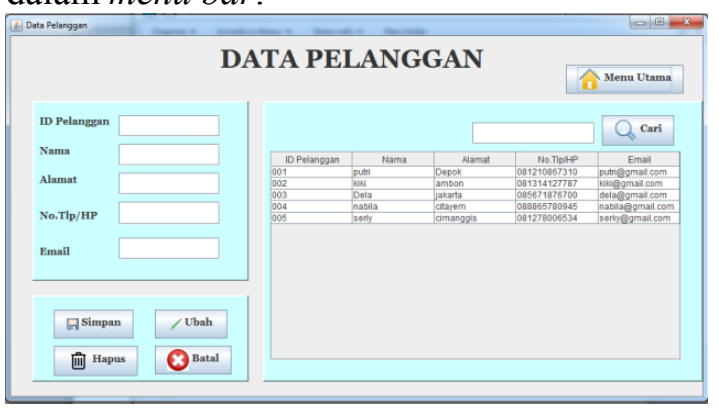

Gambar 4. Tampilan Menu Data Pelanggan

Setelah mengklik button data pelanggan, maka akan muncul data form data pelanggan. Pada layar menu utama data pelanggan terdapat tampilan tabel yang diambil dari database. Dilayar ini dapat menginput data-data pelanggan kedalam form input data seperti : Id pelanggan,nama,alamat,no tlp,email.

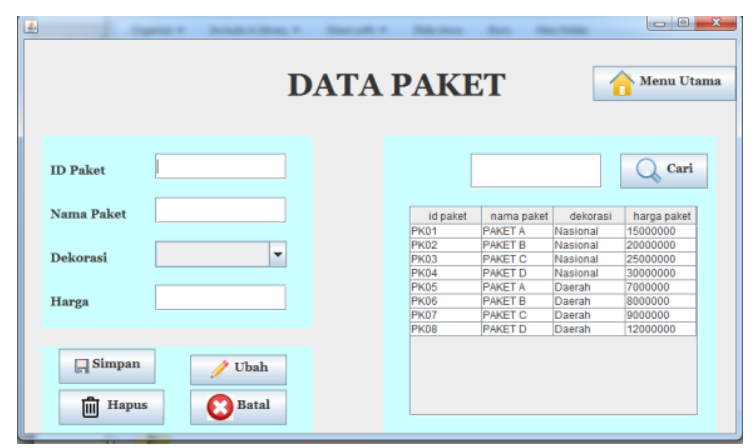

Gambar 5. Tampilan Data Paket 
Setelah mengklik button data paket, maka akan muncul data form paket yang tersedia. Pada layar menu data paket terdapat tampilan tabel yang diambil dari database. Di layar ini dapat menginput data-data id paket,nama paket, dekorasi dan harga.

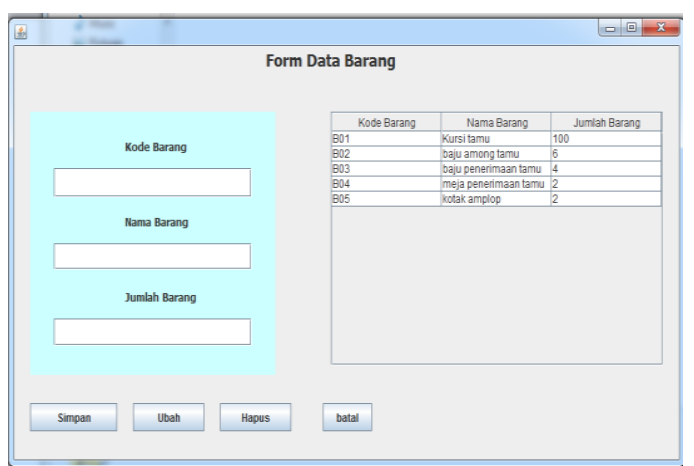

Gambar 6. Tampilan Data Barang

Setelah mengklik button data barang, maka akan muncul data form data barang. Pada form data barang terdapat tampilan tabel yang diambil dari database. Di layar ini dapat menginput data-data kode barang, nama barang dan jumlah barang.

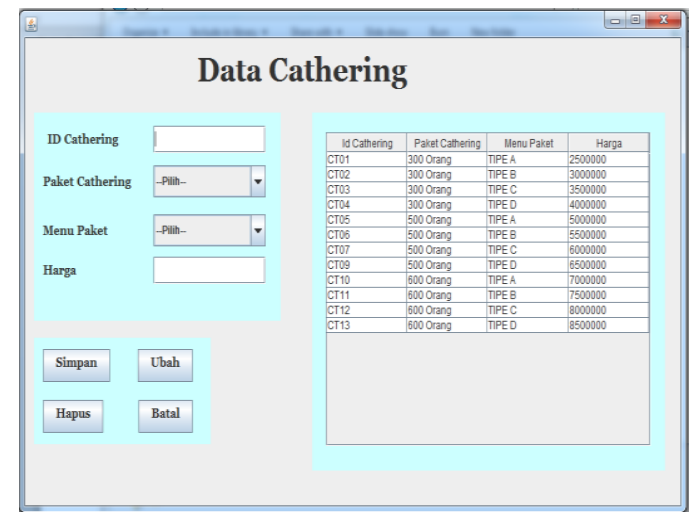

Gambar 7. Tampilan Data Catering

Setelah mengklik button data catering, maka akan muncul data form data catering. Pada form data catering terdapat tampilan tabel yang diambil dari database. Di layar ini dapat menginput data-data catering, paket cathering, menu makanan, harga makanan, menu minuman, harga minuman, menu dessert, harga dessert, total harga.

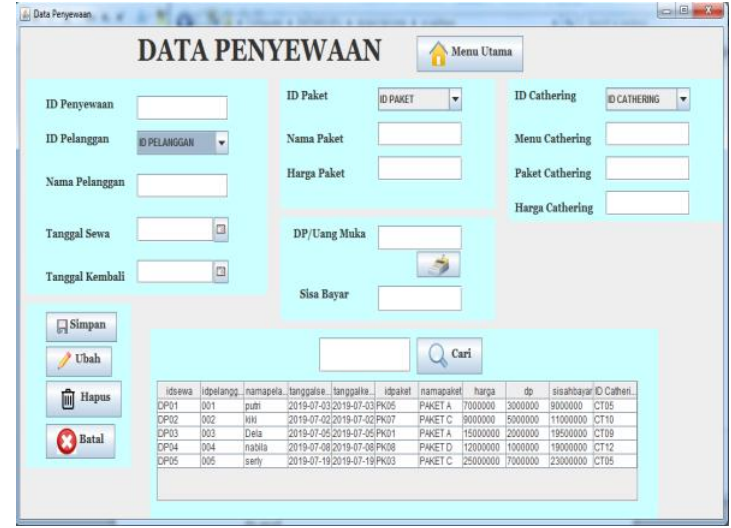

Gambar 8. Tampilan Data Penyewaan

Setelah mengklik button data penyewaan, maka akan muncul data form data penyewaan. Pada form data penyewaan terdapat tampilan tabel yang diambil dari database. Di layar ini dapat menginput datadata penyewa, id penyewaan, id pelanggan, nama pelanggan, tanggal sewa, tanggal kembali, id paket, nama paket, harga paket, id catering, menu catering, paket catering, harga catering, dp, sisa bayar.

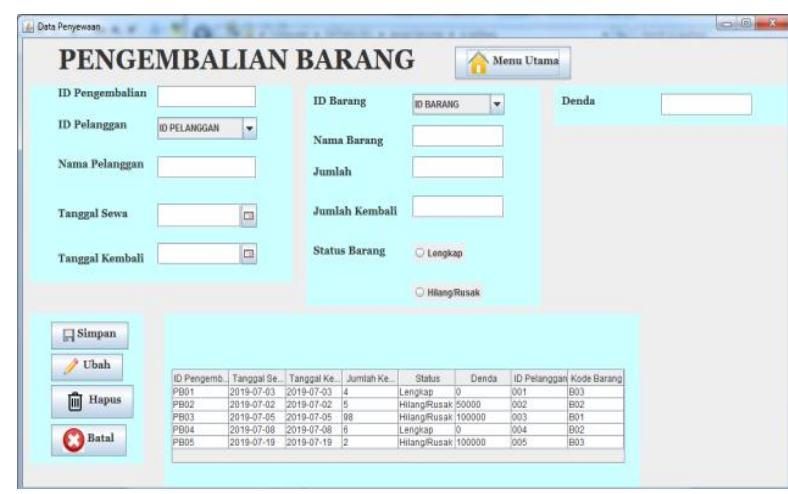

Gambar 9. Tampilan Data Pengembalian Barang

Setelah mengklik button data pengembalian barang, maka akan muncul data form data pengembalian barang. Pada form data pengembalian barang terdapat tampilan tabel yang diambil dari database. Di layar ini dapat menginput data-data id pengembalian, id pelanggan, nama pelanggan, tanggal sewa, tanggal kembali, id barang, nama barang, jumlah, jumlah kembali,status barang dan denda. 


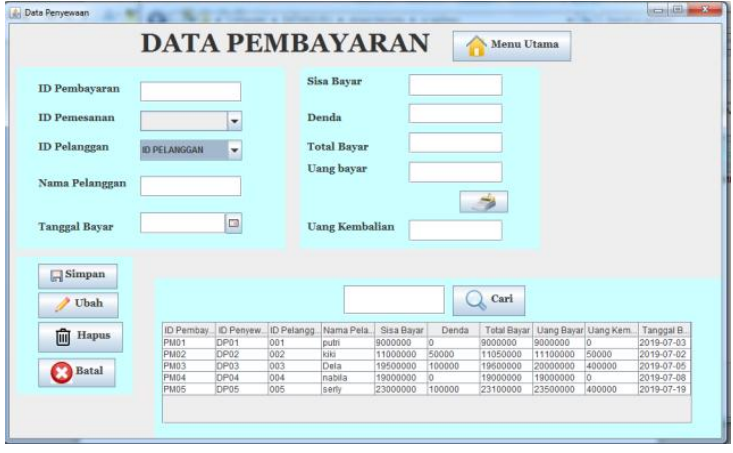

Gambar 10. Tampilan Data Pembayaran

Setelah mengklik button data pembayaran, maka akan muncul form data pembayaran. Pada form data pembayaran terdapat tampilan tabel yang diambil dari database. Di layar ini dapat menginput datadata id pembayaran, id pemesanan, id pelanggan, nama pelanggan, tanggal bayar, denda, total bayar, uang bayar dan uang kembalian.

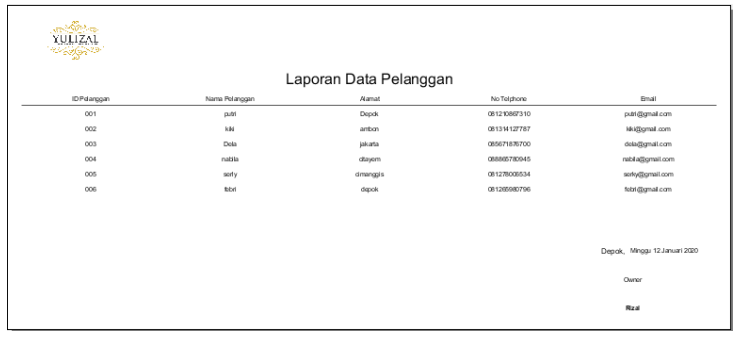

Gambar 11. Tampilan Laporan Data Penggalan

Pada laporan data pelanggan ini, berisi data-data yang telah di input pada form data pelanggan. Laporan ini muncul ketika admin mengklik tombol laporan cetak data pelanggan.

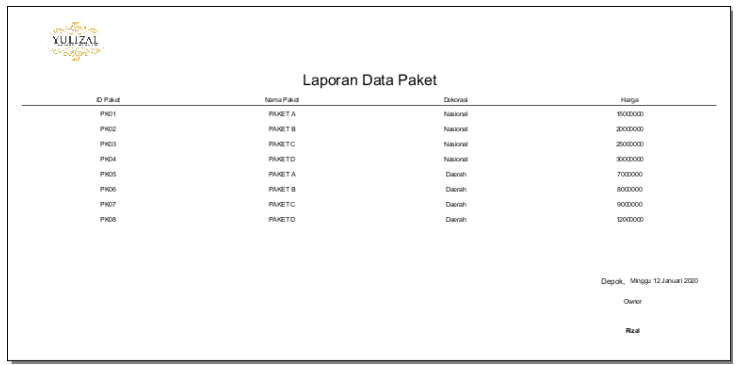

Gambar 12. Tampilan Laporan Data Paket

Pada laporan data paket ini, berisi data-data yang telah di input pada form data paket.
Laporan ini muncul ketika admin mengklik tombol laporan cetak data paket.

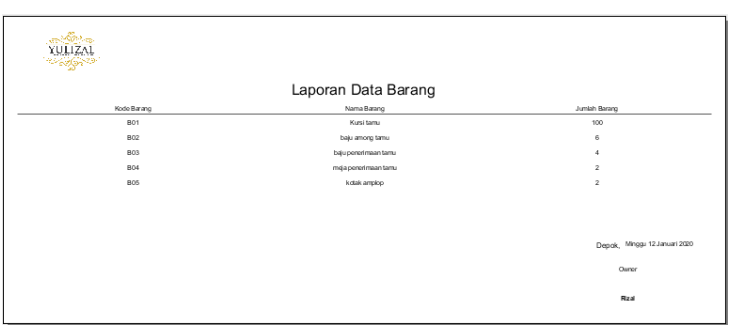

Gambar 13. Tampilan Laporan Data Barang

Pada laporan data barang ini, berisi data-data yang telah di input pada form data barang. Laporan ini muncul ketika admin mengklik tombol laporan cetak data barang.

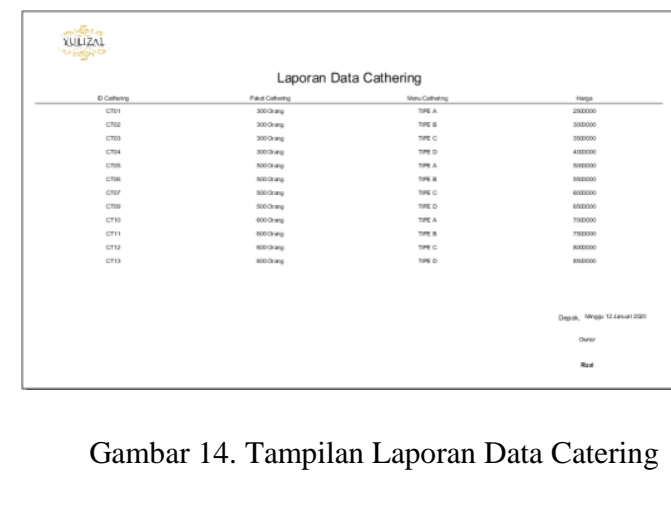

Pada laporan data Catering ini, berisi data-data yang telah di input pada form data Catering. Laporan ini muncul ketika admin mengklik tombol laporan cetak data Catering.

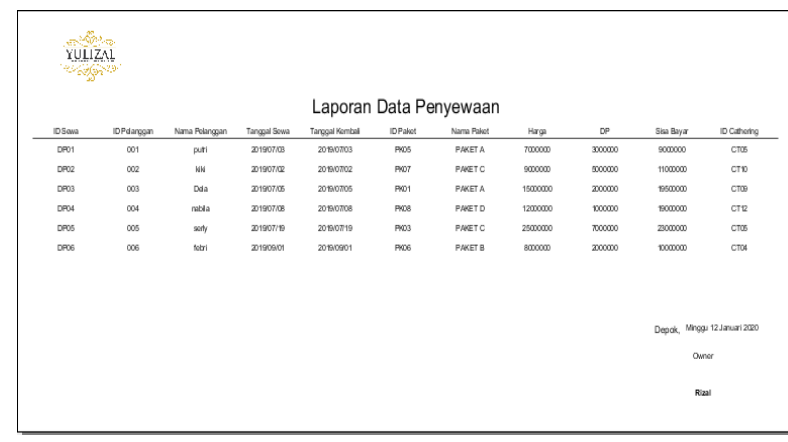

Gambar 15. Tampilan Laporan Data Penyewaan

Pada laporan data Penyewaan ini, berisi data-data yang telah di input pada form data Penyewaan. Laporan ini muncul ketika admin mengklik tombol laporan cetak data Penyewaan. 


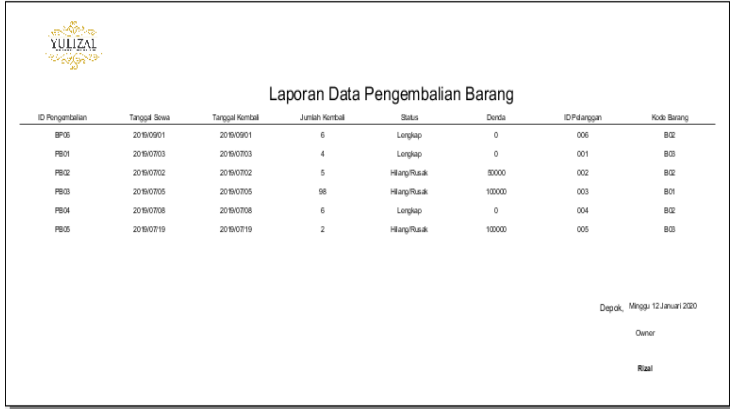

Gambar 16. Tampilan Laporan Pengembalian Barang

Pada laporan data Pengembalian Barang ini, berisi data-data yang telah di input pada form data Pengembalian Barang. Laporan ini muncul ketika admin mengklik tombol laporan cetak data Pengembalian Barang.

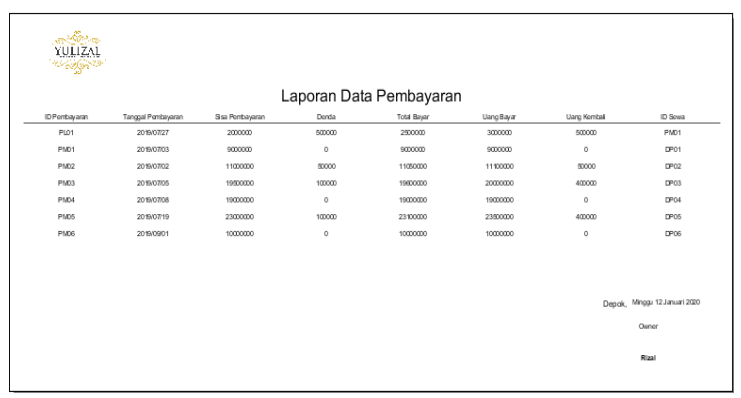

Gambar 17. Tampilan Laporan Data Pembayaran

Pada laporan data pembayaran ini, berisi data-data yang telah di input pada form data pembayaran. Laporan ini muncul ketika admin mengklik tombol laporan cetak data pembayaran.

\section{Kesimpulan}

- Dari pembahasan bab-bab sebelumnya, peneliti dapat menarik kesimpulan bahwa dengan dibuatnya perancangan aplikasi sistem penyewaan paket pernikahan dan resepsi di Yulizal Wedding yang telah terkomputerisasi sistem pengelolaan data menjadi lebih efektif dan efesien.

- Dengan adanya aplikasi ini, pengurus Yulizal Wedding dimudahkan dalam mengurus administrasi dan pengelohan datanya.
- Petugas Yulizal Wedding dimudahkan dalam mengelolah data-data pada sistem di Yulizal Wedding

\section{Daftar Pustaka}

Adi, N. (n.d.). Perancangan dan Implementasi Sistem Basis Data. CV Andi Offset.

Ali, M. (2013). Pemasaran Politik di Era Multipartai. Expose.

Kristanto, A. (n.d.). Perancangan Sistem Informasi dan Aplikasinya.

Mulyati, S., \& Hisyam, M. (2018). Rancang Bangun Sistem Informasi Penyewaan Wedding Organizer Berbasis Web Dengan Php Dan MySQL Pada Kiki Rias. Jurnal Teknik: Universitas Muhammadiyah Tangerang, 7(2), 2935.

Sutabri, T. (2012). Analisis Sistem Informasi. In Analisa Sistem Informasi.

Sutanta, E. (2011). Basis Data Dalam Tinjauan Konseptual. Andi Offset, CV.

Taniah, A. W., \& Harjunawati, S. (2017). Perancangan Sistem Informasi Transaksi Penyewaan Wedding Organizer Pada Cv.Denis Citra Mandiri Bekasi. Jurnal Ilmu Pengetahuan Dan Teknologi Komputer, 3(1), 59-64. 